\title{
Pro-inflammatory mediators and neutrophils are increased in synovial fluid from heifers with acute ruminal acidosis
}

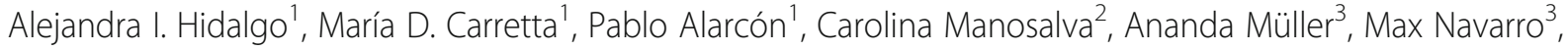 \\ María A. Hidalgo ${ }^{1}$, Thilo Kaehne ${ }^{4}$, Anja Taubert ${ }^{5}$, Carlos R. Hermosilla ${ }^{5}$ and Rafael A. Burgos ${ }^{1 *}$ (1)
}

\begin{abstract}
Background: Acute ruminal acidosis (ARA) is a metabolic disease of cattle characterized by an aseptic synovitis. ARA is the result of an increased intake of highly fermentable carbohydrates that frequently occurs in dairy cattle subjected to high production requirements. In human joint diseases such as rheumatoid arthritis and gout, several pro-inflammatory molecules are increased in the synovial fluid, including cytokines, prostaglandin $E_{2}\left(P G E_{2}\right)$, metalloproteinases, and neutrophil extracellular traps (NETs). The aim of this study was to identify the presence of proinflammatory mediators and neutrophils in the synovial fluid of heifers with ARA, induced by an oligofructose overload.

Five heifers were challenged with an oligofructose overload $(13 \mathrm{~g} / \mathrm{kg} \mathrm{BW}$ ) dissolved in water. As a control, a similar vehicle volume was used in four heifers. Synovial fluid samples were collected from the tarso-crural joint and PGE IL-6, IL-1 $\beta$, ATP, lactate dehydrogenase (LDH), albumin, glucose, matrix metalloproteinase-9 (MMP-9), cellular free DNA, NETs, and serpin B1 were analyzed at 0, 9, and $24 \mathrm{~h}$ post treatment.

Results: At $9 \mathrm{~h}$ post oligofructose overload, an increase of $\mathrm{IL}-1 \beta, \mathrm{IL}-6, \mathrm{PGE}$, serpin $\mathrm{B} 1$ and $\mathrm{LDH}$ was detected in the joints when compared to the control group. At $24 \mathrm{~h}$, the synovial fluid was yellowish, viscous, turbid, and contained abundant neutrophils. An increase of DNA-backbone-like traps, histone $3\left(\mathrm{H}_{3} \mathrm{Cit}\right)$, aggregated neutrophil extracellular traps (aggNETs), and serpin B1 were observed $24 \mathrm{~h}$ post treatment. Furthermore, albumins, LDH, ATP, MMP-9, IL-6, and IL-1 $\beta$ were increased after $24 \mathrm{~h}$.
\end{abstract}

Conclusions: The overall results indicate that IL-1 $\beta, I L-6$ and $P G E_{2}$, were the earliest proinflammatory parameters that increased in the synovial fluid of animals with ARA. Furthermore, the most sever inflammatory response in the joint was observed after $24 \mathrm{~h}$ and could be associated with a massive presence of neutrophils and release of aggNETs.

Keywords: Acute ruminal acidosis, Synovial fluid, Synovitis, Cytokine, Neutrophil extracellular traps, Prostaglandin $E_{2}$

\section{Background}

Acute ruminal acidosis (ARA) is a metabolic-nutritional disease that affects production efficiency, mainly in dairy cattle $[1,2]$. A high intake of non-structural carbohydrates, which are fermented in the rumen reduce the $\mathrm{pH}$ of the ruminal fluid causing metabolic acidosis [3]. Lameness is frequently associated with this metabolic imbalance, and the appearance of laminitis [1] and

\footnotetext{
* Correspondence: rburgos1@uach.cl

${ }^{1}$ Laboratory of Inflammation Pharmacology, Faculty of Veterinary Sciences, Institute of Pharmacology and Morphophysiology, Universidad Austral de Chile, Valdivia, Chile

Full list of author information is available at the end of the article
}

synovitis [4]. In addition, some evidence suggests the existence of a link between the disruption in gastrointestinal functionality and joint inflammation in ruminants. Acute, sterile arthritis and tenosynovitis in cattle has previously been associated with rumen acidosis (Dirksen, 2002). Hyldgaard-Jensen and Simesen (1966) observed acute, bilateral, serofibrinous arthritis in the tarsal joints after experimental induction of ruminal acidosis in one cow. Other authors reported polysynovitis in two calves and one cow with experimentally-induced ruminal acidosis with or without endotoxin exposure [5,6]. In spite of this, the findings were not documented and either the

(c) The Author(s). 2019 Open Access This article is distributed under the terms of the Creative Commons Attribution 4.0 International License (http://creativecommons.org/licenses/by/4.0/), which permits unrestricted use, distribution, and reproduction in any medium, provided you give appropriate credit to the original author(s) and the source, provide a link to the Creative Commons license, and indicate if changes were made. The Creative Commons Public Domain Dedication waiver (http://creativecommons.org/publicdomain/zero/1.0/) applies to the data made available in this article, unless otherwise stated. 
presence of pro-inflammatory markers in the joint of cattle with ARA, has not been measured yet.

In humans, high levels of pro-inflammatory cytokines and prostaglandin $\mathrm{E}_{2}\left(\mathrm{PGE}_{2}\right)$ have been found in the synovial fluid of patients with osteoarthritis [7], rheumatoid arthritis (RA) [8, 9] and gout [10, 11]. The fibroblast-like synoviocytes of RA patients trigger intracellular signaling pathways that control $\mathrm{PGE}_{2}$ and pro-inflammatory cytokine production e. g. interleukin 6 (IL-6) and interleukin1beta (IL-1 $\beta)$, through mitogen-activated protein kinases and nuclear factor-kappa B pathways [12]. In addition, neutrophils are the main innate immune cell population present in aseptic inflammatory joint diseases [13, 14], contributing to the release of matrix metalloproteinase- 9 (MMP-9) [15], pro-inflammatory cytokines [13], $\mathrm{PGE}_{2}$ [16], and neutrophil extracellular traps (NETs) $[17,18]$.

The effects of ARA on the inflammatory process in bovine joints have scarcely been studied. Some evidence suggests that heifers with ARA induced by oligofructose overload presented lameness characterized by an increased joint distention score [19] and aseptic synovitis [4]. Additionally, D-lactate can induce the release of MMP9 in vitro [20] and trigger the adhesion of bovine neutrophils to vascular endothelium through a mechanism that is dependent on the formation of NETs [21]. These antecedents suggest that during ARA there is an increase of pro-inflammatory agents and neutrophil recruitment in the synovium.

We hypothesize that in heifer with ARA induced by oligofructose overload, an increase of pro-inflammatory mediators and a large presence of neutrophils in the joint would contribute to explain the early onset of synovitis in cattle.

\section{Methods}

\section{Animals and housing}

Nine non-pregnant black Friesian dairy heifers aged 1018 months and weighing $200-250 \mathrm{~kg}$ were used in this study. The animals were obtained from Estación Experimental Agropecuaria Austral farm of the Universidad Austral de Chile and were housed in the large animal facility of the Veterinary Hospital of the Universidad Austral de Chile. The health status of the animals was verified with a clinical examination and complementary tests (hematological and biochemical analysis). In addition, the animals were free of brucellosis, leucosis, and tuberculosis, and were certified by the National Livestock Service of Chile. The animals were submitted to a 4-week period of acclimatization before the experiments were conducted and carefully handled to avoid inducing stress throughout experiment settings.

The heifers were fed twice daily. The daily ration of concentrate was equally divided into two meals of $1.0 \mathrm{~kg}$ each of $\operatorname{Cosetan}^{\circ}$ (IANSAGRO S.A., Chile), and water ad libitum. The heifers grazed on naturalized pasture composed primarily of perennial grasses, mostly Holcus lanatus and Agrostis capillaris. The contribution of forage legumes was low, $<10 \%$ of the dry matter. During the challenge heifers were fed individually twice a day and the meals were weighed to estimate consumption.

\section{Oligofructose overload}

The animals were randomly assigned into two groups, oligofructose and control. For each heifer $(n=5), 13 \mathrm{~g} / \mathrm{kg}$ of body weight (BW) of oligofructose (Orafti P95, Beneo-Alfa Group, Santiago, Chile) was dissolved in warm tap water and administered in a volume of $2 \mathrm{~L} /$ $100 \mathrm{~kg}$ of BW as a ruminal drench. The same volume of water (vehicle) was used as the control group $(n=4)$. Prior to this, $5 \%$ of the main dose was provided twice daily for 3 days before the main overload, as previously described [22, 23]. The experiment included a 3-day control period before the oligofructose overload and a $24 \mathrm{~h}$ surveillance period afterwards. All animals were clinically monitored (heart and respiratory rate, rectal temperature, ruminal frequency, and for signs of lameness) by a veterinary clinician, and all procedures were performed in the ruminant unit of the Veterinary Hospital.

Twenty-four hours after the administration of the total oligofructose dose, a solution of sodium bicarbonate $(1 \mathrm{~g} /$ $\mathrm{kg} \mathrm{BW}$ ) and ruminal restorative mineral salts (Bilifar, DragPharma, Chile) were administered orally, and analgesic/anti-inflammatory (Febrectal ${ }^{\circ}$, DragPharma, Chile)and antibiotic (Pencidrag ${ }^{\circ}$, DragPharma, Chile)-treatments were given by intramuscular injection. At the end of the study, none of animals had to be euthanized, and all fully recovered. Moreover, none of them exhibited secondary pathologies after two months of observation period. Finally, all animals returned to the farm of the Universidad Austral de Chile.

\section{Animal welfare standards}

All experiments were conducted in accordance with the guidelines for the use of animals in experimentation of the Universidad Austral de Chile, and the National Guidelines on the Use of Experimental Animals of the 'Comisión Nacional de Ciencia y Tecnología de Chile'. All animal experiments were also approved the Institutional Ethic Review Committee (No. Bioethics Report 217/2015 and No. bioethics monitoring S-49-2017).

\section{Ruminal, synovial fluid and blood sample collection}

During the following $24 \mathrm{~h}$ after the challenge, the animals were sampled to obtain ruminal and synovial fluid. Three schedules were adopted for obtaining samples: 0 $\mathrm{h}$, corresponding to samples before administration of the total dose of oligofructose; $9 \mathrm{~h}$ after the administration 
of the total dose of oligofructose, time point where an increase in plasma lactate [24] and ruminal acidosis are observed [22]; and 24 h after the administration of oligofructose overload which represented the period of maximum WBC count detected in the synovial fluid of heifers [25].

Rumenocentesis was performed in the dorsal sac of the rumen to collect ruminal fluid [26]. Afterward, the $\mathrm{pH}$ was quickly measured in a portable $\mathrm{pH}$ meter with a

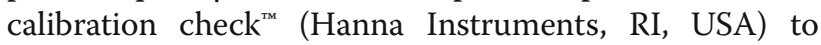
assess the ruminal acidosis experimental procedure.

To obtain synovial fluid an aseptic arthrocentesis was performed [25, 26] using an $18 \mathrm{G}$ needle of $3.8 \mathrm{~cm}$ for the collection of $3-15 \mathrm{ml}$ of fluid. The punctures were performed randomly only once in each joint, to avoid sample contamination; the puncture sites were: between the talus and the os centroquartale of the tarsal joint and between the intermediate and lateral patellar ligaments of the knee joint.

The blood sample was collected by venipuncture of the jugular vein and plasma isolation was performed according Concha et al. (2014) and stored at $-80^{\circ} \mathrm{C}$.

\section{Synovial fluid characterization}

For the physical characterization of the fluid, color was assessed by visual inspection. The $\mathrm{pH}$ was measured immediately after obtaining a sample of synovial fluid, using a portable $\mathrm{pH}$ meter (Hanna instruments, RI, USA).

\section{Cytological analysis}

Cellular characterization was performed after preparing a cellular smear. For this, $30 \mu \mathrm{l}$ of fresh synovial fluid was centrifuged at $200 \times g$ for $10 \mathrm{~min}$ in a cytospin centrifuge (Hettich, Germany). Staining was performed using a Hemacolor microscope kit (Merck ${ }^{\ominus}$, Germany). Neutrophil count was performed by observing 5 fields with an Olympus BX51 $1^{\circ}$ microscope (Olympus, Japan). The results were expressed as the average of five observed fields.

\section{Biochemical analysis}

Synovial fluid was centrifuged at $1000 \times g$ for $10 \mathrm{~min}$ at $\mathrm{RT}$, and the supernatant was stored at $-80^{\circ} \mathrm{C}$. For albumin detection, the photometric-colorimetric method bromocresol green (HUMAN Diagnostic Worldwide, Germany) was used. Glucose was estimated by using glucose oxidase-phenol and the 4-aminophenazone enzymatic colorimetric method (HUMAN Diagnostic Worldwide). For lactate dehydrogenase (LDH) the kinetic method according to the Scandinavian Committee on Enzymes (HUMAN Diagnostic Worldwide) was used. All analyses were performed in a Metrolab $2300^{\circ}$ autoanalyzer, according to the manufacturer's instructions (Wiener Lab Group, Argentina).

\section{IL-1 $\beta$, IL-6, and $\mathrm{PGE}_{2}$ measurements}

Aliquots of $200 \mu \mathrm{l}$ of synovial fluid were used to estimate the concentration of pro-inflammatory cytokines by using a bovine IL-1 $\beta$ ELISA Kit (\#ESS0027, Thermo Fisher Scientific, MA, USA) and IL-6 (\#ESS0029, Thermo Fisher Scientific, MA, USA), according to the manufacturer's instruction. Briefly, the capture antibody was incubated overnight; wells were then blocked for 1 h; subsequently, $200 \mu \mathrm{l}$ of sample was added and incubated for $1 \mathrm{~h}$. After the plates had been washed twice, the detection antibody was added and incubated for $1 \mathrm{~h}$. After further two washes, streptavidin was added and the mixture incubated for further $30 \mathrm{~min}$. Finally, tetramethylbenzidine substrate solution (TMB) was added followed by incubation for $20 \mathrm{~min}$ in the dark. All procedures were performed at RT. The reaction was stopped with $0.16 \mathrm{M} \mathrm{H}_{2} \mathrm{SO}_{4}$, and the samples were analyzed for IL-1 $\beta$ and IL- 6 at $450 \mathrm{~nm}$ and $550 \mathrm{~nm}$, respectively, in an automatic Varioskan Flash Reader (Thermo Fisher Scientific, MA, USA).

For $\mathrm{PGE}_{2}$ analysis an ELISA Kit-Monoclonal (\#514010, Cayman Chemical, MI, USA) was used according to the manufacturer's instructions. Briefly, in a 96 well plate, $50 \mu \mathrm{l}$ of ELISA buffer, $50 \mu \mathrm{l}$ of sample, $50 \mu \mathrm{l}$ of $\mathrm{PGE}_{2}$ acetylcholinesterase tracer, and $\mathrm{PGE}_{2}$ monoclonal antibody were combined. The incubation was performed for $18 \mathrm{~h}$ at $4{ }^{\circ} \mathrm{C}$. The next day, the contents of each well were washed 5 times and $200 \mu$ of Ellman's reagent was added, followed by agitation in the dark for $90 \mathrm{~min}$. Finally, the plate was analyzed at 405 and $420 \mathrm{~nm}$ in a Varioskan Flash Reader (Thermo Fisher Scientific MA, USA).

\section{ATP measurement}

A CellTiter-Glo ${ }^{\mathrm{mi}}$ luminescent cell viability assay (Promega, WI, USA) was used according to the manufacturer's instructions. Briefly, equal volumes of synovial fluid and CellTiter-Glo ${ }^{\text {тm }}$ Reagent $(50 \mu \mathrm{l})$ were added, mixed for 4 min on an orbital shaker and then incubated at RT for $10 \mathrm{~min}$. Luminescent analysis was performed in a Varioskan Flash Reader (Thermo Fisher Scientific, MA, USA).

\section{Zymography}

Synovial fluid samples were centrifuged at $1000 \times g 10$ min and the supernatant was stored at $-80^{\circ} \mathrm{C}$. MMP-9 activity was carried out by zymography [27]. Briefly, the sample was diluted 1:10 in distilled water, and $4 \mu \mathrm{l}$ was loaded onto $10 \%$ polyacrylamide gels $(0.75 \mathrm{~mm}$ thick $)$ containing $0.28 \%$ gelatin. The gels were run at $200 \mathrm{~V}$ for $1 \mathrm{~h}$ in a Bio-Rad Mini Protean II apparatus (Bio-Rad Laboratories, CA, USA) and then washed thrice in $2.5 \%$ Triton X-100 in distilled water on a shaker at RT for 30 min. Subsequently, the gels were incubated in reaction 
buffer consisting of $100 \mathrm{mM}$ Tris (pH 7.5) and $10 \mathrm{mM}$ $\mathrm{CaCl}_{2}$ at $37^{\circ} \mathrm{C}$ overnight. The gels were stained with 0.5\% Coomassie Brilliant Blue R-250 (Winkler, Santiago, Chile) in a solution of acetic acid, methanol, and water (1:3:6). Gelatinase activity was determined by the observation of non-staining areas in which the gelatin was degraded. Calculation of the apparent molecular masses of the gelatinolytic bands was estimated by using a prestained molecular mass marker (Fermentas International Inc., Canada). Band intensity was determined using Image 1.51 j8 software.

\section{Cellular free DNA (cf-DNA)}

cf-DNA was measured to evaluate NET formation [28]. For quantification of cf-DNA, $200 \mu \mathrm{l}$ of freshly extracted synovial fluid was used. Samples were incubated with $0.5 \mathrm{U} / \mathrm{ml}$ per well of micrococcal nuclease (New England Biolabs, USA) for $30 \mathrm{~min}$ at $37^{\circ} \mathrm{C}$. Then samples were centrifuged at $500 \times g$ for $5 \mathrm{~min}$ at RT. Afterwards, $100 \mu \mathrm{l}$ of supernatant was transferred to a new well and $100 \mu \mathrm{l}$ of Quant-iT ${ }^{\mathrm{Tm}}$ PicoGreen ${ }^{\mathrm{Tw}}$ dye (Thermo Fisher Scientific, MA, USA) diluted in TE buffer $(10 \mathrm{mM}$ Tris, $1 \mathrm{mM}$ EDTA) was added. Analysis was performed using an automated Varioskan Flash Reader (Thermo Fisher Scientific, MA, USA) at $484 \mathrm{~nm}$ excitation and $520 \mathrm{~nm}$ emission, as described elsewhere [29].

\section{Western blot}

Synovial fluid (stored at $-80^{\circ} \mathrm{C}$ ) was used to quantify total protein using the Bradford colorimetric method [30]. For this, $50 \mu \mathrm{g}$ of total protein were separated on $12 \%$ SDS-PAGE gels at $100 \mathrm{~V}$ for $2 \mathrm{~h}$ and transferred onto PVDF membranes at $200 \mathrm{~mA}$ for $2 \mathrm{~h}$. Membranes were then blocked in Tris-buffered saline with Tween-20 (TBS-T) buffer $(10 \mathrm{mM}$ Tris- $\mathrm{HCl}, 68 \mathrm{mM} \mathrm{NaCl}$, and $0.1 \%$ Tween-20) and 5\% non-fat dry milk for $2 \mathrm{~h}$ at RT and washed with TBS-T. The primary antibodies used were: histone $\mathrm{H} 3$ (citrulline $\mathrm{R} 2+\mathrm{R} 8+\mathrm{R} 17 ; \mathrm{H}_{3}$ cit) antibody (\#ab5103, Abcam, UK) and serpin B1 antibody (\#ARP52417_P050, Aviva Systems Biology, CA. USA) incubated at $4{ }^{\circ} \mathrm{C}$ in constant agitation overnight. Thereafter secondary antibodies [anti-rabbit IRDye 800 and 680 (Li-cor Biosciences, USA)] were used. Analysis of membranes was performed by using a LI-COR OdysseyFc system (LI-COR Biosciences, NE, USA) and densitometry was quantified using the Image 1.51 j8 software.

\section{Fluorescence microscopy}

Aliquots of $100 \mu \mathrm{l}$ of fresh synovial fluid were placed on slides and fixed with $2 \%$ paraformaldehyde for $15 \mathrm{~min}$ at RT, then washed twice with cold PBS. Primary antibody histone H3 [citrulline R2 + R8 + R17] ( $\mathrm{H}_{3}$ cit) (\#ab5103, Abcam, United Kingdom) was incubated overnight at $4{ }^{\circ} \mathrm{C}$. The following day the secondary antibody, Alexa
Fluor 594 (\#A11037, Invitrogen, USA), was incubated for $2 \mathrm{~h}$ at RT. Finally, DNA was stained with Quant-iT $\mathrm{T}^{\mathrm{mm}}$ PicoGreen $^{\mathrm{Th}}$ dye (Thermo Fisher Scientific, MA, USA). Images were acquired with an OLYMPUS ${ }^{\circ}$ Fluoview 1000 confocal microscope.

\section{Statistical analyses}

Since our data do not show normal distribution and variance homogeneity according to Shappiro-Wilks and Bartlett's test respectively, a Mann-Withney test for nonparametric data was used. A P-value $<0.05$ was considered as significant. Data were depicted in bar graph as mean \pm S.E.M. All analyses were performed using the GraphPad Prism ${ }^{\circ}$ software (v 5.0, Graphpad Software, CA, USA).

\section{Results}

Physical changes and increase of neutrophils in the synovial fluid of heifers with ARA

To experimentally induce ARA in heifers, we used the oligofructose overload protocol [22]. A decrease of ruminal $\mathrm{pH}<5.0$ as clinical diagnostic criteria of ARA was used [31]. In fact, at $9 \mathrm{~h}$ and $24 \mathrm{~h}$ the experimental procedure significantly reduced the ruminal $\mathrm{pH}$ to around 4.5, confirming ARA induction (Fig. 1).

The synovial fluid of the animals before induction, at 0 $\mathrm{h}$, was colorless, transparent, and had a fluid consistency; similar findings were observed after $9 \mathrm{~h}$. At $24 \mathrm{~h}$, the animals were weak, slow-moving, prone to decubitus, anorexic, and presented explosive liquid diarrhea. At $9 \mathrm{~h}$ and $24 \mathrm{~h}$, all animals treated with oligofructose overloads showed lameness resulting in a locomotion score of 2-3 [32]. In addition, at $24 \mathrm{~h}$, there was an evident physical change in synovial fluid, which became yellowish, viscous, and turbid. Additionally, after $24 \mathrm{~h}$, a marked increase in neutrophil content within synovial fluid was detected (Fig. 2).

As described elsewhere [4], microbiological analysis of all synovial samples were negative (data not shown).

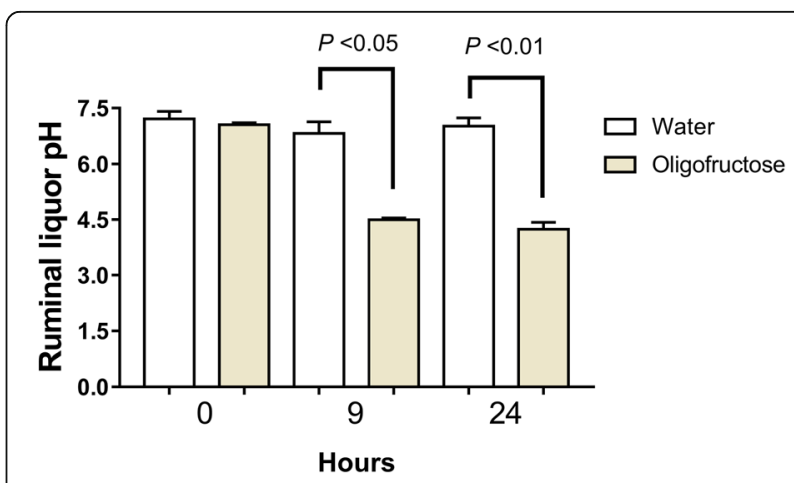

Fig. 1 Ruminal pH at 0, 9, and $24 \mathrm{~h}$ post overload of oligofructose and water administration. Each bar represent mean \pm SEM 
IL-1 $\beta, I L-6$, PGE $_{2}$, ATP, and MMP-9 increased in the synovial fluid of heifers with ARA

The concentration of several inflammatory parameters such as IL-1 $\beta$, IL-6, PGE 2 , ATP and MMP-9 in the synovial fluid, were assessed in animals with ARA. At $9 \mathrm{~h}$ IL-1 $\beta$, IL-6, PGE 2 showed a significant increase compared to the vehicle which was more evident after $24 \mathrm{~h}$ (Fig. 3A-C). In plasma samples did not observe any significant changes in these proinflammatory parameters (Additional file 1).

ATP is a metabolite with a pro-inflammatory role in joints [33] and in a similar fashion we observed a significant ATP increase $(P<0.05)$ at $24 \mathrm{~h}$ (Fig. 3D). Because neutrophil recruitment was detected at $24 \mathrm{~h}$, and these cells release MMP-9 from intracellular granules, we assessed MMP-9 activity in joints using zymography. An increase of MMP-9 activity was recorded only at $24 \mathrm{~h}$ (Fig. 4).

\section{Presence of aggNETs, histone citrunillated 3, and serpin B1 in the synovial fluid of heifers with ARA}

The presence of NETs in synovial fluid is a hallmark in the joint aseptic inflammatory process [14, 34]; for this we assessed the presence of DNA traps in synovial fluid. First, a significant increase in cf-DNA was observed in the synovial fluid of animals at $24 \mathrm{~h}$ (Fig. 5A). We confirmed the formation of NETs by fluorescence microscopy. The presence of aggNETs decorated with $\mathrm{H}_{3}$ cit were visualized in synovial fluids of ARA suffering heifers (Fig. 5B). Furthermore, the presence of $\mathrm{H}_{3}$ cit at $24 \mathrm{~h}$ was confirmed by Western blot analysis (Fig. 5B). In addition, we observed an increase in serpin B1 at $9 \mathrm{~h}$

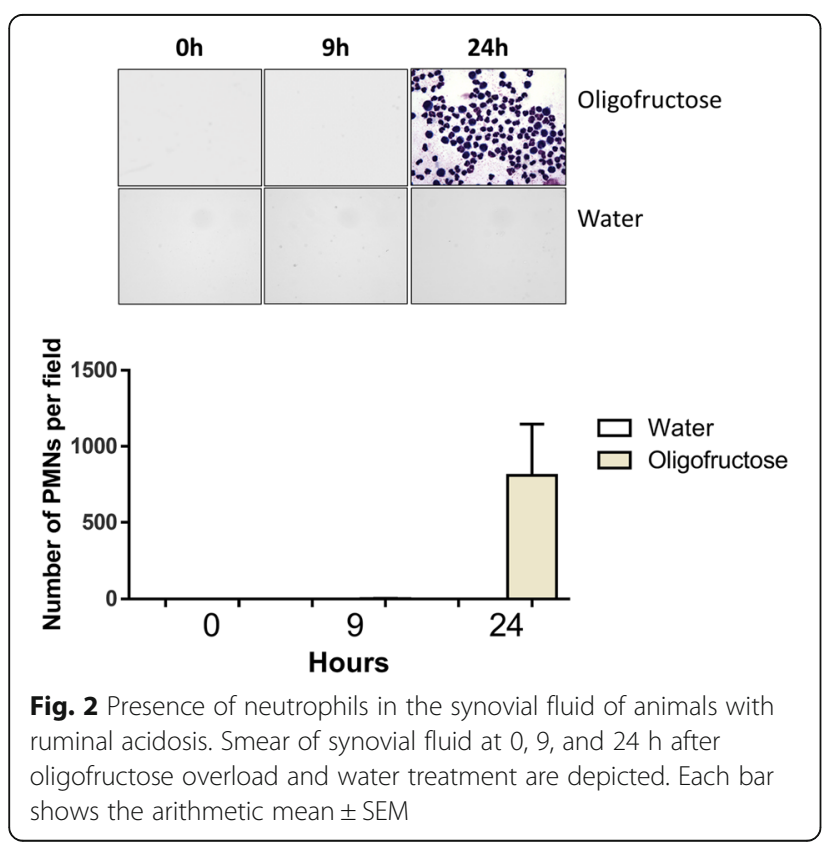

and $24 \mathrm{~h}$ in the synovial fluid of heifers with ARA (Fig. 5C).

\section{$\mathrm{LDH}$ and albumin were increased in the synovial fluid of heifers with ARA}

Some biochemical indicators in synovial fluid have a diagnostic value in joint diseases [35-38]. To assess biochemical changes in the synovial fluid of heifers with ARA we analyzed albumin, LDH and glucose levels. A significant increase in LDH at $9 \mathrm{~h}$ and $24 \mathrm{~h}$ were observed (Fig. 6a). At $24 \mathrm{~h}$ a significant increase in albumin was detected (Fig. 6b). In plasma samples no significant changes for these LDH and albumin parameters were observed (Additional file 1). In contrast, glucose did not change during ARA induction (Fig. 6c).

\section{Discussion}

Ruminal acidosis induces lameness in cattle and previously reported evidence suggests that joint inflammation could be involved [19], however this condition has not been fully characterized. During ARA an increase of pro-inflammatory cytokines IL-6 and IL-1 $\beta$ were observed in the joint at $9 \mathrm{~h}$ and $24 \mathrm{~h}$. Lenski and Scherer (2014) [39] recorded an increase in the concentration of IL-6, being the best inflammatory marker for predicting periprosthetic joint infections, however also can be detected in excess in aseptic joint diseases [40-42]. IL-1 $\beta$ is responsible for monocyte survival in the joint [43], and promoting leukocyte attachment and the production of metalloproteinases involved in articular degradation [43] and inflammation [44, 45]. Regardless, in horses synovial fluid IL-1 $\beta$ has no predictive value because of the wide variation obtained in clinically normal joints; which represent the population most likely to have the diagnostic test for evaluating lameness [46]. Therefore, the increase of IL-1 $\beta$ observed in the joints of heifers should be carefully considered as a predictive parameter of lameness in cattle. We detected a high concentration of $\mathrm{PGE}_{2}$ in the synovial fluid from heifers with ruminal acidosis; this is a well-known lipid mediator of several joint diseases $[47,48]$. Since the increase was observed at $9 \mathrm{~h}$, before neutrophil recruitment, it could be closely related with a possible synoviocyte response in the joint.

Synovitis in heifers with ARA was clinically observed at $24 \mathrm{~h}$ and characterized by an increase of total protein concentrations and abundant WBC values [4]. An increase of leukocytes in synovial fluids of cattle suffering arthritis has been previously described [49]. However, an increase of polymorphonuclear neutrophils (PMN) in ruminants has only been associated with infectious arthritis caused by direct inoculation of microorganisms into the joint capsule, extension from periarticular injuries, or by hematogenous spread [49]. Some authors described that the systemic inflammatory response during 


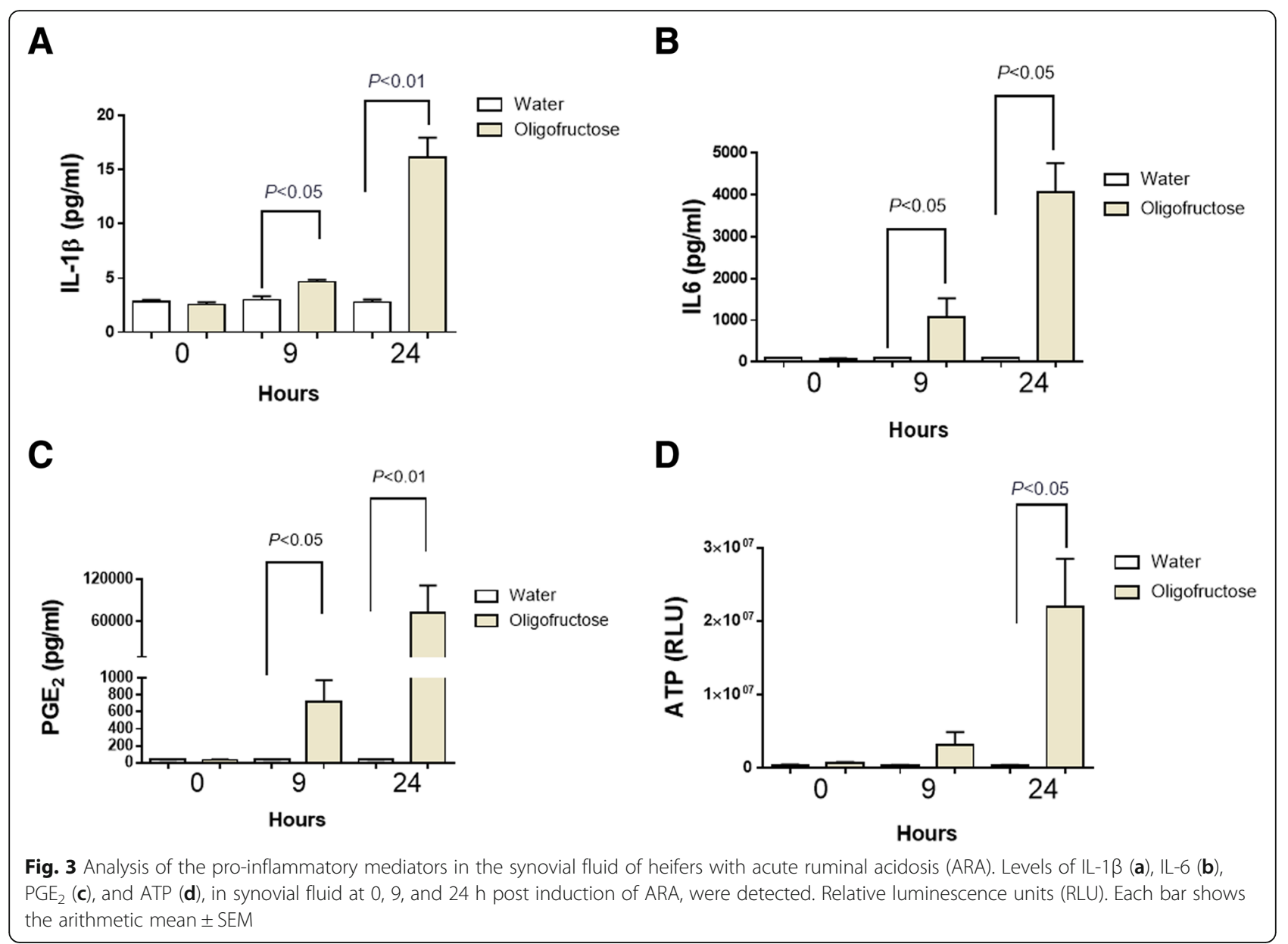

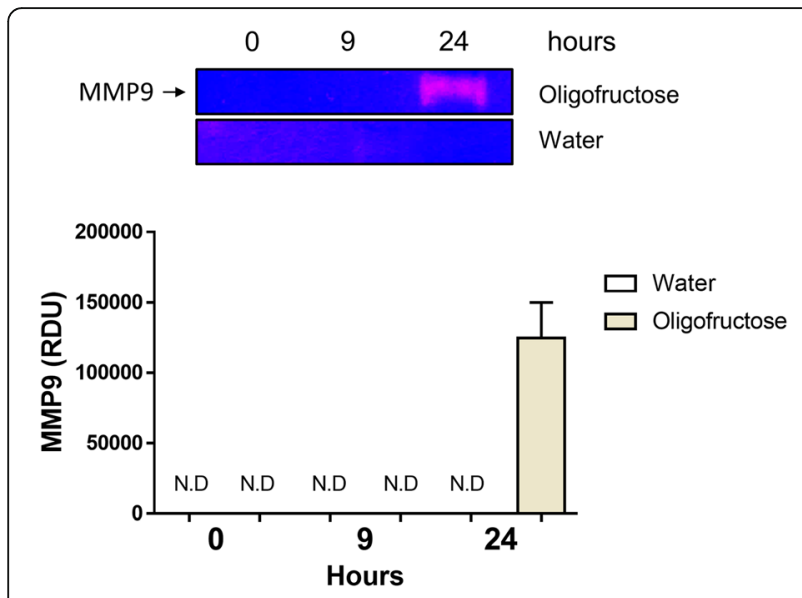

Fig. 4 Presence of MMP-9 in the synovial fluid of heifers with ARA. A representative zymography is depicted. Each bar shows the arithmetic mean \pm SEM of relative unit of densitometry (RDU). N.D. none detected acute ruminal acidosis could be related to bacterial infection, possibly due to translocation of lipopolysaccharide (LPS) into the peripheral circulation from the rumen [50]. On the contrary, we did not observed changes in proinflammatory parameters in plasma, suggesting non-apparent systemic inflammation. Moreover, other authors demonstrate that the inflammatory processes in the locomotor apparatus during ARA are aseptic [39]. In addition, synovial fluid from animals with ARA, synovitis induced by oligofructose overload, was negative for the presence of bacteria (data not shown); thus being considered by other authors as an aseptic synovitis condition [51]. Therefore, other non-infectious agents/molecules might be involved in the synovium activation during ARA. Until now, the detailed molecular mechanisms to explain on how the pro-inflammatory cascade conveyed from rumen to the joint are still unknown. However, it has been suggested that vasoactive substances produced in the bovine rumen, such as, lactate, histamine, tyramine and tryptamine, might be capable to induce inflammatory processes in the locomotor apparatus of cattle [1]. 

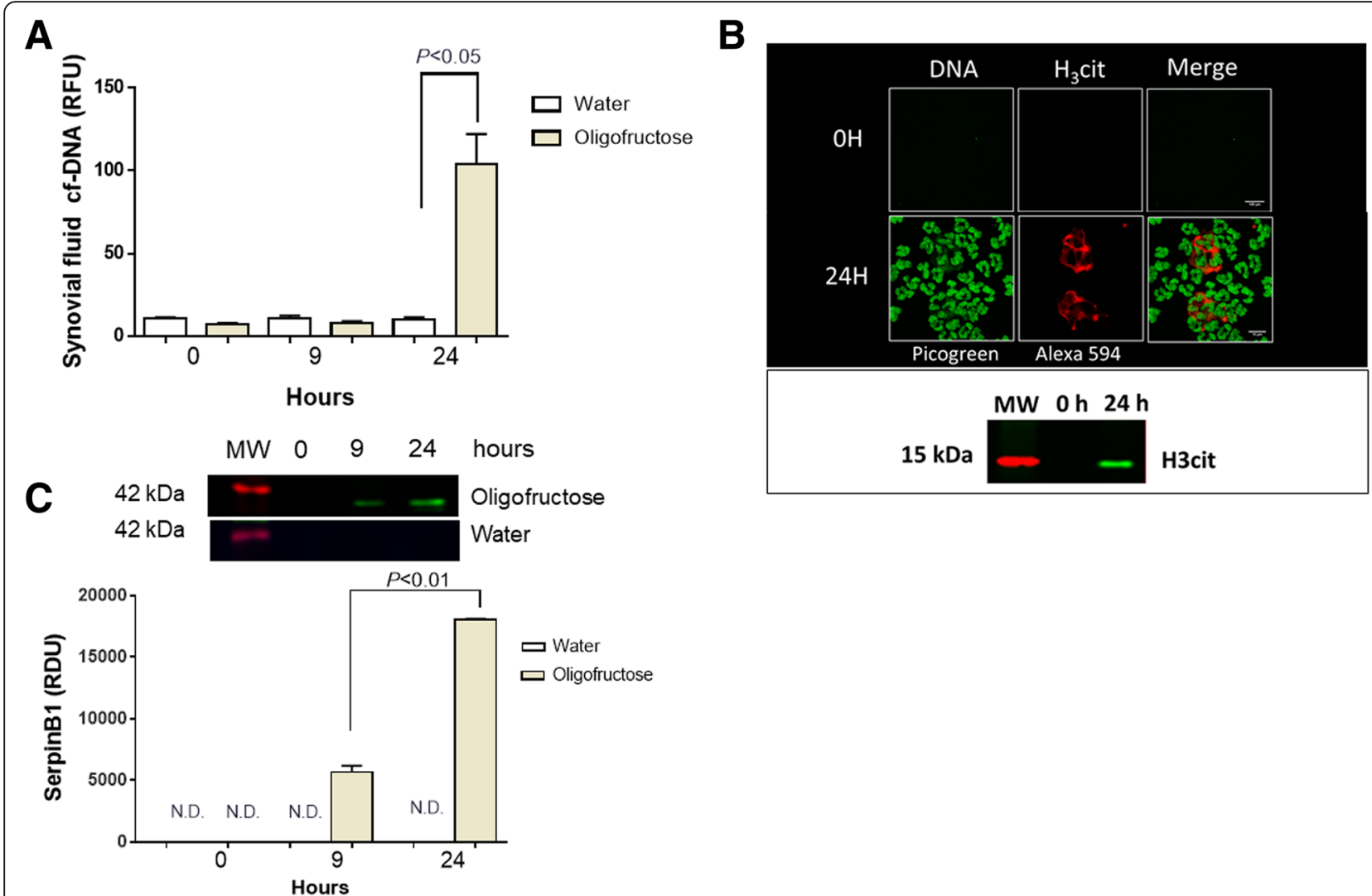

Fig. 5 Determination of neutrophil extracellular traps (NETs) and serpin B1 in the synovial fluid of heifers with acute ruminal acidosis (ARA). a cfDNA measurement at 0, 9, and $24 \mathrm{~h}$. Relative fluorescence units (RFU). $\mathbf{b}$ Immunofluorescence of synovial fluid at $0 \mathrm{~h}$ and $24 \mathrm{~h}$ after the induction of ARA. Histone $\mathrm{H} 3$ cit and DNA at $24 \mathrm{~h}$ post induction was observed. A representative western blot of synovial fluid to detect $\mathrm{H}_{3} \mathrm{cit}$ at $24 \mathrm{~h}$ post induction is shown. Scale bar $100 \mu \mathrm{m}$ and $10 \mu \mathrm{m}$ for $0 \mathrm{~h}$ and $24 \mathrm{~h}$ respectively. c Immunoblot of serpin B1 at 0,9 , and $24 \mathrm{~h}$ in the synovial fluid. A bar graph of the relative densitometry units (RDU) of serpin B1 is shown. Each bar shows the arithmetic mean \pm SEM. N.D. none detected

An increase of ATP concentration in bovine synovial fluid has also been observed in osteoarthritis, sodium urate-induced synovitis in dogs [33], and in arthritis induced in rats [52]. Therefore, extracellular ATP concentrations are nowadays considered as important proinflammatory agents [53]. Since ATP was observed at $24 \mathrm{~h}$, this suggests that either neutrophils $[54,55]$ or synovium [52] can contribute to the release of ATP into the joint.

The increase of MMP-9 activity in synovial fluid from heifers with ARA could be related to the presence of neutrophils in the joint [56], however other cells could also be responsible $[57,58]$. In support of this, the synovium as well as leukocytes release MMP-9 contributing to the increase observed in the inflammed joint [58]. The synovial lumen and membrane sections of joints obtained from heifers, both at $24 \mathrm{~h}$ and $72 \mathrm{~h}$ after oligofructose overload, showed infiltration of neutrophils into the subintima as well as neutrophil accumulation within the synovial lumen [4]. The increase of MMP-9 in the joints of heifers could be closely associated with leukocyte migration and damage observed in tissues adjacent to affected joints.
More importantly, an increase of neutrophils, cf-DNA, and release of aggNETs at $24 \mathrm{~h}$ in the synovial fluid of heifers with ARA were documented suggesting a potential contribution of aggNETs in synovitis. Consistently, in human metabolic gout disease also aggNETs were reported to occur in affected joints [59] Peptidylarginine deiminases 4 (PAD4) mediates histone citrullination and promotes NETosis by inducing chromatin decondensation and facilitating the expulsion of chromosomal DNA [60]. In synovial fluid from heifers with ARA, we observed the presence of H3cit decorating aggNETs, which have been involved in inflammatory resolution, having the ability to degrade pro-inflammatory cytokines [61]. This suggests that in the joint of heifers with ARA, an aggNETs-derived anti-inflammatory mechanism might simultaneously occur, but this speculation request further investigations. In connection with this, we demonstrated the presence of serpin B1 in synovial fluid at $9 \mathrm{~h}$ and $24 \mathrm{~h}$, a protein which inhibits neutrophil serine proteases [62] and also able to suppress NETosis [63]. Therefore, an increase in serpin B1 in synovial fluids during acute ruminal acidosis could be related to its 


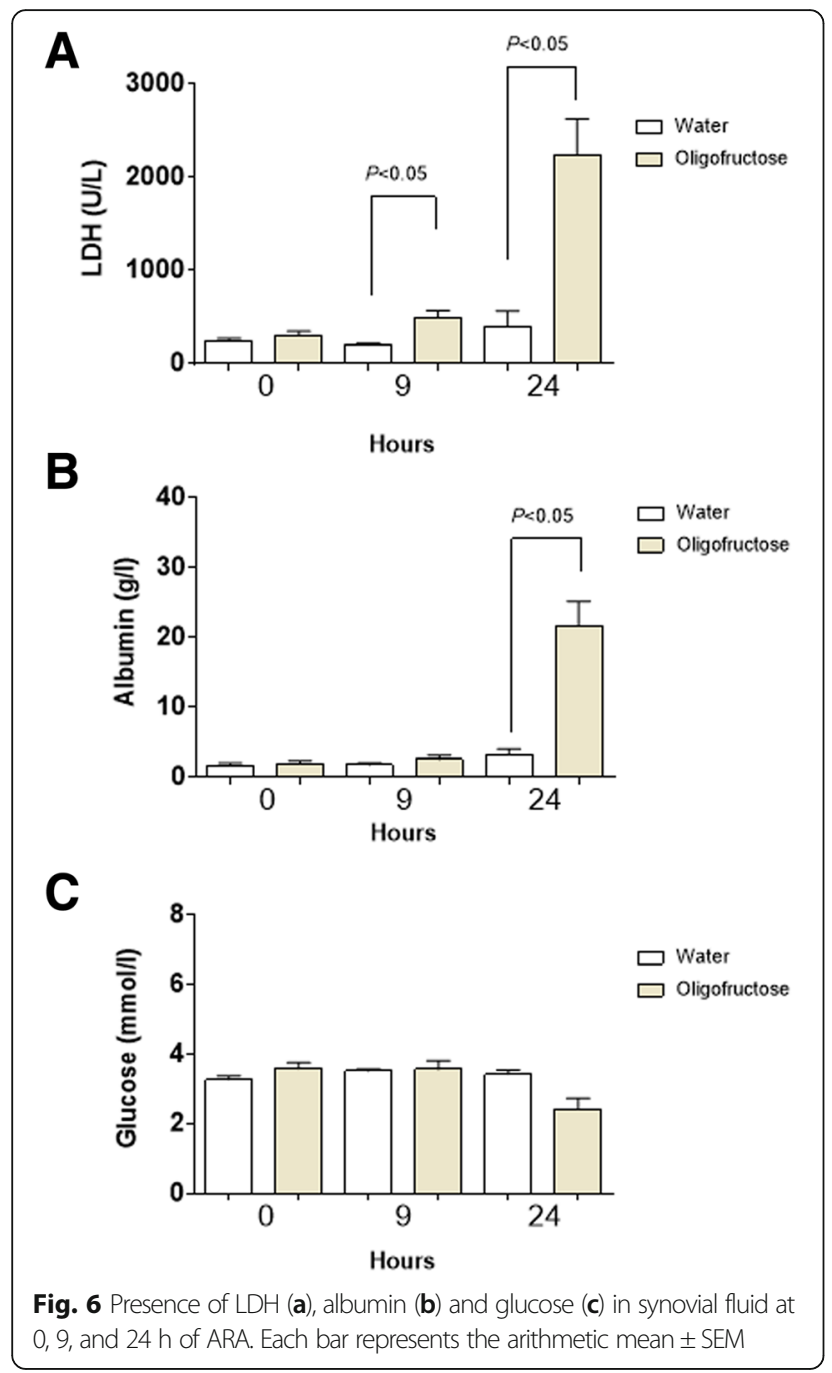

ability to resolve inflammatory processes [64] in the joint [65]. Furthermore, other authors using a similar experimental procedure, described that the grade of joint inflammation in dairy heifers is decreased after $24 \mathrm{~h}$ of oligofructose overload [4].

During joint inflammation several biochemical markers have been used to characterize and differentiate specific diseases. In the synovial fluid of heifers with ARA a significant increase of albumins and $\mathrm{LDH}$ were recorded. Since albumin is only synthesized in the liver [66], its increased concentration in the synovial fluid would indicate an increase in the vascular permeability of affected joints [67]; which could be responsible for the rise in synovial fluid volume observed in the joints of heifers showing ARA-associated clinical manisfestations [4]. In connection with this, the increase of IL-1 $\beta$, IL- 6 , and PGE2, all of them considered as potent vascular permeability-inducing agents, might also contribute to explain the increase of albumin and plasma extravasation into joint fluids [67-69].
The increase of LDH enzyme $>2000 \mathrm{U} / \mathrm{l}$ in the synovial fluid of heifer with ruminal acidosis was higher than the levels described for clinical intact join in cattle [70] and could be a possible marker of inflammation [36]. The current study found no changes in glucose levels, which agrees with previous findings stating that there is no increase in glucose levels in the synovial fluid during non-infectious joint diseases [39, 71, 72].

\section{Conclusions}

Our data suggest that the joints in heifers with ARA induced by oligofructose overloads resulted not only in an acute inflammatory response with enhanced neutrophils

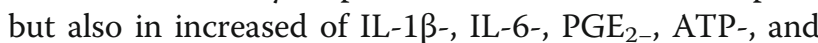
MMP-9-levels within synovial fluids. Simultaneously the presence of aggNETs and serpin B1 expression suggest a rather fine-tuning modulation of pro-inflammatory process in affected joints. Aseptic synovitis associated with disorders of reticuloruminal fermentative functions might therefore represent a clinical entity most probably underestimated in cattle industry.

\section{Additional file}

Additional file 1: Table S1. Plasmatic pro-inflammatory (IL-1 $\beta, I L-6$ and $\left.P G E_{2}\right)$ and biochemical (LDH, albumin) parameters of heifers with ARA. (DOCX $14 \mathrm{~kb}$ )

\section{Abbreviations}

aggNETs: Aggregated NETs; ARA: Acute ruminal acidosis; ATP: Adenosine triphosphate; BW: Body weight; CD11b: Cluster of differentiation molecule 11b; cf-DNA: Cellular free DNA; COX-2: Cyclooxygenase-2; ELISA: Enzymelinked immunosorbent assay; H3cit: Histone H3 citrullinated; HIF-1a: Hypoxiainducible factor-1 alpha; ICAM-1: Intercellular adhesion molecule-1; IL1ß: Interleukin-1 beta; IL-6: Interleukin-6; LDH: Lactate dehydrogenase; LPS: Lipopolysaccharide; MMP-9: Matrix metalloproteinase-9; NETs: Neutrophil extracellular traps; PGE 2 : Prostaglandin $\mathrm{E}_{2} ;$ PMN: Polymorphonuclear neutrophils; PVDF: Polyvinylidene difluoride; RT: Room temperature; SDS-

PAGE: Sodium dodecyl sulfate-polyacrylamide gel electrophoresis;

SEM: Standard error mean; TBS-T: Tris-buffered saline with Tween-20;

WBC: white blood cells

\section{Acknowledgements}

We would like to thank the animal keepers Daniel Huequeman and Gerardo Peña, both of the Veterinary Clinical Sciences Institute staff, for all their excellent support with animal handling and performing the experimental trials.

\section{Authors' contributions}

AlH, MDC, MN performed the experiments and drafted the manuscript; MDC and $C M$ helped with the animal experimentation and the ELISA bioassay experiments; AM, performed the biochemical analysis. TK helped with serpin B1 detection. AT, CH and PA helped with NETs detection experiments and cf-DNA estimation. MAH and RBA designed the entire study and assisted in drafting the manuscript. All authors read and approved the final manuscript.

\section{Funding}

This work was supported by the 'Fondo Nacional de Desarrollo Científico y Tecnológico' (Grant FONDECYT No. 1151035; 1180946); Scholarship 'Comisión Nacional de Investigación Científica y Tecnológica (CONICYT) Doctorado Nacional - Doctorado 2014' (Folio number 21140760). The funders had neither role in study design, data collection, analysis, the decision to publish, nor the preparation of the manuscript. 


\section{Availability of data and materials}

All data generated or analyzed during the study are included in this published article. The datasets used and/or analyzed during the present research project are available from the corresponding author on reasonable request.

\section{Ethics approval and consent to participate}

The animal experiment protocol was approved by the 'Comision Nacional de Ciencia y Tecnologia de Chile (Approval Number: 217/2015)' and performed in accordance with the guidelines and regulations of the committee.

\section{Consent for publication}

Non-applicable.

\section{Competing interests}

The authors declare that they have no competing interests.

\section{Author details}

'Laboratory of Inflammation Pharmacology, Faculty of Veterinary Sciences, Institute of Pharmacology and Morphophysiology, Universidad Austral de Chile, Valdivia, Chile. ${ }^{2}$ Faculty of Sciences, Institute of Pharmacy, Universidad Austral de Chile, Valdivia, Chile. ${ }^{3}$ Veterinary Clinical Sciences Institute, Faculty of Veterinary Sciences, Universidad Austral de Chile, Valdivia, Chile. ${ }^{4}$ Institute of Experimental Internal Medicine, Otto-von-Guericke University Magdeburg, Leipziger Strasse 44-0, 39120 Magdeburg, Germany. ${ }^{5}$ Institute of Parasitology, Faculty of Veterinary Medicine, Justus Liebig University Giessen, 35392 Giessen, Germany.

\section{Received: 7 December 2018 Accepted: 23 June 2019} Published online: 03 July 2019

\section{References}

1. Hernandez J, Benedito JL, Abuelo A, Castillo C. Ruminal acidosis in feedlot: from aetiology to prevention. TheScientificWorldJournal. 2014;2014:702572

2. Zebeli Q, Metzler-Zebeli BU. Interplay between rumen digestive disorders and diet-induced inflammation in dairy cattle. Res Vet Sci. 2012;93(3):1099-108.

3. Harmon DL, Britton RA, Prior RL, Stock RA. Net portal absorption of lactate and volatile fatty acids in steers experiencing glucose-induced acidosis or fed a 70\% concentrate diet ad libitum. J Anim Sci. 1985;60(2):560-9.

4. Danscher AM, Enemark HL, Andersen PH, Aalbaek B, Nielsen OL. Polysynovitis after oligofructose overload in dairy cattle. J Comp Pathol. 2010;142(2-3):129-38.

5. Mortensen KW: Bovine laminitis: diffuse aseptic Pododermatitis. PhD thesis. Denmark: Københavns Universitet; 1993.

6. Mortensen K, Hesselholt M, A B: Pathogenesis of bovine laminitis (diffuse aseptic pododermatitis). Experimental models. In: Proceedings of the 14th World Congress on Diseases of Cattle. Dublin; 1986: 1025-1030.

7. Haseeb A, Haqqi TM. Immunopathogenesis of osteoarthritis. Clin Immunol. 2013;146(3):185-96.

8. Guo Q, Wang Y, Xu D, Nossent J, Pavlos NJ, Xu J. Rheumatoid arthritis: pathological mechanisms and modern pharmacologic therapies. Bone research. 2018;6:15.

9. Hoxha M. A systematic review on the role of eicosanoid pathways in rheumatoid arthritis. Adv Med Sci. 2018;63(1):22-9.

10. Ramonda R, Oliviero F, Galozzi P, Frallonardo P, Lorenzin M, Ortolan A, Scanu A, Punzi L. Molecular mechanisms of pain in crystal-induced arthritis. Best Pract Res Clin Rheumatol. 2015;29(1):98-110.

11. So AK, Martinon F. Inflammation in gout: mechanisms and therapeutic targets. Nat Rev Rheumatol. 2017;13(11):639-47.

12. Zou Y, Zeng S, Huang M, Qiu Q, Xiao Y, Shi M, Zhan Z, Liang L, Yang X, Xu H. Inhibition of 6-phosphofructo-2-kinase suppresses fibroblast-like synoviocytes-mediated synovial inflammation and joint destruction in rheumatoid arthritis. Br J Pharmacol. 2017;174(9):893-908.

13. Rada B. Neutrophil extracellular traps and microcrystals. J Immunol Res. 2017;2017:2896380.

14. Wright HL, Moots RJ, Edwards SW. The multifactorial role of neutrophils in rheumatoid arthritis. Nat Rev Rheumatol. 2014;10(10):593-601.

15. Ramanathan K, Glaser A, Lythgoe H, Ong J, Beresford MW, Midgley A, Wright HL. Neutrophil activation signature in juvenile idiopathic arthritis indicates the presence of low-density granulocytes. Rheumatology (Oxford). 2018;57(3):488-98.

16. Weissmann $\mathrm{G}$, Korchak H. Rheumatoid arthritis. The role of neutrophil activation. Inflammation. 1984;8(Suppl):S3-14.

17. Apel F, Zychlinsky A, Kenny EF. The role of neutrophil extracellular traps in rheumatic diseases. Nat Rev Rheumatol. 2018

18. Desai J, Steiger S, Anders HJ. Molecular pathophysiology of gout. Trends Mol Med. 2017;23(8):756-68.

19. Danscher AM, Enemark JMD, Telezhenko E, Capion N, Ekstrøm CT, Thoefner MB. Oligofructose overload induces lameness in cattle. J Dairy Sci. 2009; 92(2):607-16

20. Alarcon P, Conejeros I, Carretta MD, Concha C, Jara E, Tadich N, Hidalgo MA, Burgos RA. D-lactic acid interferes with the effects of platelet activating factor on bovine neutrophils. Vet Immunol Immunopathol. 2011;144(1-2): 68-78.

21. Alarcon P, Manosalva C, Conejeros I, Carretta MD, Munoz-Caro T, Silva LMR, Taubert A, Hermosilla C, Hidalgo MA, Burgos RA. d(-) lactic acid-induced adhesion of bovine neutrophils onto endothelial cells is dependent on neutrophils extracellular traps formation and CD11b expression. Front Immunol. 2017:8:975.

22. Concha C, Carretta MD, Alarcon P, Conejeros I, Gallardo D, Hidalgo Al, Tadich N, Caceres DD, Hidalgo MA, Burgos RA. Oxidative response of neutrophils to platelet-activating factor is altered during acute ruminal acidosis induced by oligofructose in heifers. J Vet Sci. 2014;15(2):217-24.

23. Thoefner MB, Pollitt CC, Van Eps AW, Milinovich GJ, Trott DJ, Wattle O, Andersen PH. Acute bovine laminitis: a new induction model using alimentary oligofructose overload. J Dairy Sci. 2004;87(9):2932-40.

24. Noro M, Sepúlveda P, Cárdenas F, Chihuailaf R, Wittwer F. Rumenocentesis dorsomedial: un procedimiento seguro para la obtención de líquido ruminal en vacas lecheras a pastoreo. Arch med vet. 2013;45:25-31.

25. Bedard S, Desrochers A, Fecteau G, Higgins R: Comparison of four protocols for preoperative preparation in cattle. Can Vet J 2001, 42(3):199-203.

26. Francoz D, Desrochers A, Latouche JS. Effect of repeated arthrocentesis and single joint lavage on cytologic evaluation of synovial fluid in 5 young calves. Can J Vet Res. 2007;71(2):129-34.

27. Mena J, Manosalva C, Ramirez R, Chandia L, Carroza D, Loaiza A, Burgos RA, Hidalgo MA. Linoleic acid increases adhesion, chemotaxis, granule release, intracellular calcium mobilisation, MAPK phosphorylation and gene expression in bovine neutrophils. Vet Immunol Immunopathol. 2013;151(34):275-84.

28. Keshari RS, Jyoti A, Kumar S, Dubey M, Verma A, Srinag BS, Krishnamurthy $H$, Barthwal MK, Dikshit M. Neutrophil extracellular traps contain mitochondrial as well as nuclear DNA and exhibit inflammatory potential. Cytometry A. 2012;81(3):238-47.

29. Munoz-Caro T, Mena Huertas SJ, Conejeros I, Alarcon P, Hidalgo MA, Burgos RA, Hermosilla C, Taubert A. Eimeria bovis-triggered neutrophil extracellular trap formation is CD11b-, ERK 1/2-, p38 MAP kinase- and SOCE-dependent. Vet Res. 2015;46:23.

30. Bradford MM. A rapid and sensitive method for the quantitation of microgram quantities of protein utilizing the principle of protein-dye binding. Anal Biochem. 1976;72:248-54.

31. Marchesini G, De Nardi R, Gianesella M, Stefani AL, Morgante M, Barberio A, Andrighetto I, Segato S. Effect of induced ruminal acidosis on blood variables in heifers. BMC Vet Res. 2013;9:98.

32. Thomsen PT, Munksgaard L, Togersen FA. Evaluation of a lameness scoring system for dairy cows. J Dairy Sci. 2008;91(1):119-26.

33. Torres BT, Jimenez DA, Budsberg SC. Elevated synovial fluid concentration of adenosine triphosphate in dogs with osteoarthritis or sodium urate-induced synovitis of the stifle. Vet Comp Orthop Traumatol. 2016;29(4):344-6.

34. Maueroder C, Kienhofer D, Hahn J, Schauer C, Manger B, Schett G, Herrmann M, Hoffmann MH. How neutrophil extracellular traps orchestrate the local immune response in gout. J Mol Med (Berl). 2015;93(7):727-34.

35. Liu W, He J, Lin R, Liang J, Luo Q. Differential proteomics of the synovial membrane between bilateral and unilateral knee osteoarthritis in surgeryinduced rabbit models. Mol Med Rep. 2016;14(3):2243-9.

36. Pejovic M, Stankovic A, Mitrovic DR. Lactate dehydrogenase activity and its isoenzymes in serum and synovial fluid of patients with rheumatoid arthritis and osteoarthritis. J Rheumatol. 1992;19(4):529-33.

37. Shahid M, Manchi G, Brunnberg L, Raila J. Use of proteomic analysis to determine the protein constituents of synovial fluid samples from the stifle 
joints of dogs with and without osteoarthritis secondary to cranial cruciate ligament rupture. Am J Vet Res. 2018;79(4):397-403.

38. Teloh HA. Clinical pathology of synovial fluid. Ann Clin Lab Sci. 1975;5(4): 282-7.

39. Lenski M, Scherer MA. Analysis of synovial inflammatory markers to differ infectious from gouty arthritis. Clin Biochem. 2014;47(1-2):49-55.

40. Darrieutort-Laffite C, Boutet MA, Chatelais M, Brion R, Blanchard F, Heymann D, Le Goff B. IL-1 beta and TNFalpha promote monocyte viability through the induction of GM-CSF expression by rheumatoid arthritis synovial fibroblasts. Mediat Inflamm. 2014;2014:241840.

41. Narazaki M, Tanaka T, Kishimoto T. The role and therapeutic targeting of IL-6 in rheumatoid arthritis. Expert Rev Clin Immunol. 2017;13(6):535-51.

42. Punzi L, Calo L, Plebani M. Clinical significance of cytokine determination in synovial fluid. Crit Rev Clin Lab Sci. 2002;39(1):63-88.

43. Ospelt C. Synovial fibroblasts in 2017. RMD Open. 2017;3(2):e000471.

44. Mitroulis I, Kambas K, Ritis K. Neutrophils, IL-1ß, and gout: is there a link? Semin Immunopathol. 2013;35(4):501-12.

45. Shiozawa S, Tsumiyama K, Yoshida K, Hashiramoto A. Pathogenesis of joint destruction in rheumatoid arthritis. Arch Immunol Ther Exp. 2011;59(2):8995.

46. Bertone AL, Palmer JL, Jones J. Synovial fluid cytokines and eicosanoids as markers of joint disease in horses. Veterinary surgery : VS. 2001;30(6):528-38.

47. Frisbie DD, Al-Sobayil F, Billinghurst RC, Kawcak CE, Mcllwraith CW. Changes in synovial fluid and serum biomarkers with exercise and early osteoarthritis in horses. Osteoarthr Cartil. 2008;16(10):1196-204.

48. Kawahara K, Hohjoh H, Inazumi T, Tsuchiya S, Sugimoto Y. Prostaglandin E2induced inflammation: relevance of prostaglandin E receptors. Biochim Biophys Acta. 2015;1851(4):414-21.

49. Rohde C, Anderson DE, Desrochers A, St-Jean G, Hull BL, Rings DM. Synovial fluid analysis in cattle: a review of 130 cases. Vet Surg. 2000;29(4):341-6.

50. Minuti A, Ahmed S, Trevisi E, Piccioli-Cappelli F, Bertoni G, Jahan N, Bani P. Experimental acute rumen acidosis in sheep: consequences on clinical, rumen, and gastrointestinal permeability conditions and blood chemistry. J Anim Sci. 2014;92(9):3966-77.

51. Jazayeri JA, Carroll GJ, Vernallis AB. Interleukin-6 subfamily cytokines and rheumatoid arthritis: role of antagonists. Int Immunopharmacol. 2010; 10(1):1-8.

52. Hu F, Hui Z, Wei W, Yang J, Chen Z, Guo B, Xing F, Zhang X, Pan L, Xu J. Hypotonic stress promotes ATP release, reactive oxygen species production and cell proliferation via TRPV4 activation in rheumatoid arthritis rat synovial fibroblasts. Biochem Biophys Res Commun. 2017;486(1):108-15.

53. Cauwels A, Rogge E, Vandendriessche B, Shiva S, Brouckaert P. Extracellular ATP drives systemic inflammation, tissue damage and mortality. Cell Death Dis. 2014(5):e1102.

54. Bao Y, Ledderose C, Seier T, Graf AF, Brix B, Chong E, Junger WG. Mitochondria regulate neutrophil activation by generating ATP for autocrine purinergic signaling. J Biol Chem. 2014;289(39):26794-803.

55. Ledderose C, Bao Y, Zhang J, Junger WG. Novel method for real-time monitoring of ATP release reveals multiple phases of autocrine purinergic signalling during immune cell activation. Acta Physiol. 2015;213(2):334-45.

56. Li X, Zhao X, Ma S. Secretion of $92 \mathrm{kDa}$ gelatinase (MMP-9) by bovine neutrophils. Vet Immunol Immunopathol. 1999;67(3):247-58.

57. Troeberg L, Nagase H. Measurement of matrix metalloproteinase activities in the medium of cultured synoviocytes using zymography. Methods Mol Biol. 2003:225:77-87.

58. Zhou M, Qin S, Chu Y, Wang F, Chen L, Lu Y. Immunolocalization of MMP-2 and MMP-9 in human rheumatoid synovium. Int J Clin Exp Pathol. 2014;7(6): 3048-56.

59. Schauer $C$, Janko $C$, Munoz $L E$, Zhao $Y$, Kienhofer D, Frey B, Lell M, Manger B, Rech J, Naschberger E, et al. Aggregated neutrophil extracellular traps limit inflammation by degrading cytokines and chemokines. Nat Med. 2014; 20(5):511-7.

60. Rohrbach AS, Slade DJ, Thompson PR, Mowen KA. Activation of PAD4 in NET formation. Front Immunol. 2012(3):360

61. Hahn J, Schauer C, Czegley C, Kling L, Petru L, Schmid B, Weidner D, Reinwald C, Biermann MHC, Blunder S, et al. Aggregated neutrophil extracellular traps resolve inflammation by proteolysis of cytokines and chemokines and protection from antiproteases. FASEB J. 2019;33(1):1401-14.

62. Farley K, Stolley JM, Zhao P, Cooley J, Remold-O'Donnell E. A serpinB1 regulatory mechanism is essential for restricting neutrophil extracellular trap generation. J Immunol. 2012;189(9):4574-81.
63. Majewski P, Majchrzak-Gorecka M, Grygier B, Skrzeczynska-Moncznik J, Osiecka O, Cichy J. Inhibitors of serine proteases in regulating the production and function of neutrophil extracellular traps. Front Immunol. 2016:7:261.

64. Torriglia A, Martin E, Jaadane I. The hidden side of SERPINB1/leukocyte elastase inhibitor. Semin Cell Dev Biol. 2017;62:178-86.

65. Balakrishnan L, Bhattacharjee M, Ahmad S, Nirujogi RS, Renuse S, Subbannayya Y, Marimuthu A, Srikanth SM, Raju R, Dhillon M et al: Differential proteomic analysis of synovial fluid from rheumatoid arthritis and osteoarthritis patients. Clin Proteomics 2014, 11(1):1.

66. Emerson TE Jr. Unique features of albumin: a brief review. Crit Care Med. 1989;17(7):690-4.

67. Green PG, Luo J, Heller PH, Levine JD. Effect of E-type prostaglandins on bradykinin-induced plasma extravasation in the knee joint of the rat. Eur J Pharmacol. 1994:252(2):127-32.

68. Gurkan OU, He C, Zielinski R, Rabb H, King LS, Dodd-o JM, D'Alessio FR, Aggarwal N, Pearse D, Becker PM. Interleukin-6 mediates pulmonary vascular permeability in a two-hit model of ventilator-associated lung injury. Exp Lung Res. 2011;37(10):575-84.

69. Puhlmann M, Weinreich DM, Farma JM, Carroll NM, Turner EM, Alexander $H R$, Jr: Interleukin-1 beta induced vascular permeability is dependent on induction of endothelial tissue factor (TF) activity. J Transl Med 2005, 3:37.

70. Grun E, Panndorf $H$, Schuhmacher U. Occurrence of various enzymes in synovial fluid of cattle and swine. Arch Exp Veterinarmed. 1978;32(6):907-20.

71. Brannan SR, Jerrard DA. Synovial fluid analysis. J Emerg Med. 2006;30(3):331-9.

72. Dechant JE, Symm WA, Nieto JE. Comparison of $\mathrm{pH}$, lactate, and glucose analysis of equine synovial fluid using a portable clinical analyzer with a bench-top blood gas analyzer. Vet Surg. 2011;40(7):811-6.

\section{Publisher's Note}

Springer Nature remains neutral with regard to jurisdictional claims in published maps and institutional affiliations.

Ready to submit your research? Choose BMC and benefit from:

- fast, convenient online submission

- thorough peer review by experienced researchers in your field

- rapid publication on acceptance

- support for research data, including large and complex data types

- gold Open Access which fosters wider collaboration and increased citations

- maximum visibility for your research: over $100 \mathrm{M}$ website views per year

At $\mathrm{BMC}$, research is always in progress.

Learn more biomedcentral.com/submissions 